\title{
Improved wind system using non-linear power control
}

\author{
Yasmine Ihedrane $^{1}$, Chakib EI Bekkali ${ }^{2}$, Madiha El Ghamrasni ${ }^{3}$, Sara Mensou ${ }^{4}$, Badre Bossoufi $^{5}$ \\ ${ }^{1,2,5}$ LISTA Laboratory, Faculty of Sciences, University Sidi Mohammed Ben Abdellah FE, Morocco \\ ${ }^{3}$ EPCT Laboratory, EEEM School Mohammed V University, Morocco \\ ${ }^{4}$ Communication Networks Department of ENSIAS, Mohammed V University, Morocco \\ ${ }^{5}$ EEM Laboratory, Higher School of Technology, Mohammed I University, Morocco
}

\begin{tabular}{l}
\hline \hline Article Info \\
\hline Article history: \\
Received Nov 14, 2018 \\
Revised Jan 15, 2019 \\
Accepted Jan 29, 2019 \\
\hline Keywords: \\
Backstepping controller \\
DFIG \\
MPPT \\
Sliding mode controller \\
Wind system
\end{tabular}

\begin{abstract}
This article, present a new contribution to the control of wind energy systems, a robust nonlinear control of active and reactive power with the use of the Backstepping and Sliding Mode Control approach based on a doubly fed Induction Generator power (DFIG-Generator) in order to reduce the response time of the wind system. In the first step, a control strategy of the MPPT for the extraction of the maximum power of the turbine generator is presented. Subsequently, the Backstepping control technique followed by the sliding mode applied to the wind systems will be presented. These two types of control system rely on the stability of the system using the LYAPUNOV technique. Simulation results show performance in terms of set point tracking, stability and robustness versus wind speed variation.
\end{abstract}

Copyright $(2019$ Institute of Advanced Engineering and Science. All rights reserved.

\section{Corresponding Author:}

Yasmine Ihedrane,

LISTA Laboratory, Faculty of Sciences.

University Sidi Mohammed Ben Abdellah FEZ, Morocco.

Email: yasmine.ihedrane@usmba.ac.ma

\section{INTRODUCTION}

Currently, DFIG-based variable speed wind turbines are most commonly used in wind farms because of its high efficiency, energy quality and the ability to control the power supplied to the grid, as well as the ability to operate in $\mathrm{a} \pm 30 \%$ speed range around the synchronous speed, thanks to the design of the three-phase static converters for a portion of the $\pm 30 \%$ nominal power, which makes it possible to reduce the losses in the electronic power components and the overall increase of the system. However, the disadvantage of the DFIG-based wind turbine is that it is very sensitive to load disturbances, turbine rotational speed variation, and variation in internal and external system parameters. Likewise, the double-fed Induction generator is characterized by a nonlinear and multi-variable mathematical model with a strong coupling between the input variables. [1]i.e it is not possible to independently control the voltage or current. For this reason, many implementation works of linear models-based approaches have been applied, but the linear controller approach has quickly shown its limits, that is why research is oriented towards non-linear techniques to increase the robustness and precision of the systems to be controlled. The main idea of this approach is to analyze the stability of the nonlinear system without solving the differential equations of this system. It is a very powerful tool for testing and finding sufficient conditions for the stability of different dynamic systems. The study presented in this article aims to optimize the energy performance of a wind turbine to maximize captured wind energy while reducing the problems mentioned above and improving control performance by reducing response time. This optimization is able to minimize the costs of generating electricity. Among these techniques, we find the sliding mode control known for its robustness to changes in external parameters and disturbances, but the disadvantage of this type of control lies in the CHATTERING phenomenon which makes it possible to destabilize the system. The second technique is the non-adaptive 
BACKSTEPPING control which gives the stability of the nonlinear system, the good tracking ... etc, but which is sensitive to parametric variations [2], [3].

In this article, we will carry out a comparative study between the Sliding Mode control techniques and BACKSTEPPING in order to improve the performances of the wind system. We will start by exposing a monetization of the wind turbines. Then, a study of the operating point and maximum power tracking technique will be presented. Subsequently, we present a DFIG model in the "dq" framework and the general principle of controlling both power converters based on the Backstepping and the Sliding Mode control strategy.

\section{WIND SYSTEM MODELLING}

The wind system is mainly composed of the wind turbine, gearbox, the doubly fed induction generator whose stator is directly connected to the grid and the rotor is connected via the Rotor Side Converter (RSC) and the Grid Side Converter (GSC) as shown in Figure 1.

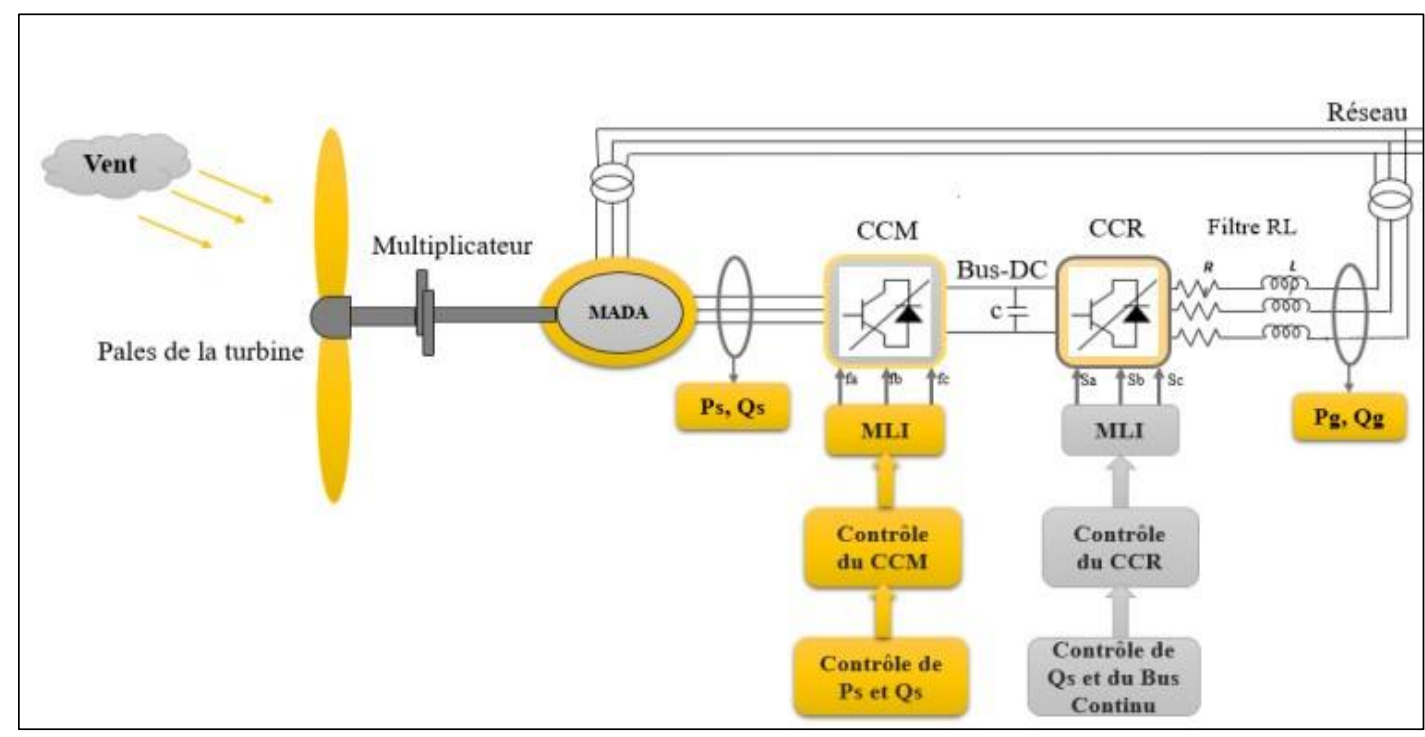

Figure 1. Global wind energy conversion system

\subsection{Wind Turbine Model}

The power generated by the wind turbine is modeled from the following [4-8]:

$$
\left\{\begin{array}{c}
P_{v}=\frac{1}{2} \cdot \rho \cdot \pi \cdot R^{2} \cdot v^{3} \\
P_{\text {aero }}=\frac{1}{2} \cdot C_{p}(\lambda, \beta) \cdot \rho \cdot \pi \cdot R^{2} \cdot v^{3} \\
\lambda=\frac{R \cdot \Omega}{v} \\
C_{g}=\frac{C_{a e r o}}{G} \\
\Omega_{t}=\frac{\Omega_{m e c}}{G} \\
\mathrm{C}_{\mathrm{p}}\left((\lambda, \beta)=\mathrm{C}_{1}\left(\frac{\mathrm{C}_{2}}{\mathrm{~A}}-\mathrm{C}_{3} \cdot \beta-\mathrm{C} 4\right) * \exp \left(-\mathrm{C}_{5} *\left(\frac{1}{(\lambda+0.08 \cdot \beta)}-\frac{0.035}{\beta^{3}+1}\right)\right)+\mathrm{C}_{6} \cdot \lambda\right.
\end{array}\right.
$$

\subsection{Standalone DFIG Model}

The Doubly Fed Induction Generator DFIG model using Park transformation is presented by the following [4-18], [20]: 


$$
\left\{\begin{array}{c}
v_{s d}=R_{s} \cdot I_{s d}+\frac{d \phi_{s d}}{d t}-\omega_{s} \cdot \phi_{s q} \\
v_{s q}=R_{s} \cdot I_{s q}+\frac{d \phi_{s q}}{d t}+\omega_{s} \cdot \phi_{s d} \\
v_{r d}=R_{r} \cdot I_{r d}+\frac{d \phi_{r d}}{d t}-\omega_{r} \cdot \phi_{r q} \\
v_{r q}=R_{r} \cdot I_{r q}+\frac{d \phi_{r q}}{d t}+\omega_{r} \cdot \phi_{r d} \\
\Phi_{s d}=L_{s} \cdot I_{s d}+\mathrm{M} \cdot I_{r d} \\
\Phi_{s q}=L_{s} \cdot I_{s q}+\mathrm{M} \cdot I_{r q} \\
\Phi_{r d}=L_{r} \cdot I_{r d}+M \cdot I_{s d} \\
\Phi_{r q}=L_{r} \cdot I_{r q}+M \cdot I_{s q} \\
C_{e m}=p \cdot\left(\Phi_{s d} \cdot I_{s q}-\Phi_{s q} \cdot I_{s d}\right) \\
P_{s}=v_{s d} \cdot I_{s d}+v_{s q} \cdot I_{s q} \\
Q_{s}=v_{s q} \cdot I_{s d}-v_{s d} \cdot I_{s q}
\end{array}\right.
$$

\subsection{Filter (R,L) Model}

The GSC Converter is connected to the DC-BUS and the Grid via a filter (Rf, Lf). It has two roles: sustaining the DC- BUS voltageconstance regarding the amplitude and the rotor power directionand maintaining a unit power factor at the link point to the grid [21]. The filter model in the referential (d, q) is given by (3):

$$
\left\{\begin{array}{l}
v_{d f}=-R_{f} I_{d f}-L_{f} \frac{d I_{d f}}{d t}+\omega_{s} L_{f} I_{q f}+v_{s d} \\
v_{q f}=-R_{f} I_{q f}-L_{f} \frac{d I_{q f}}{d t}-\omega_{s} L_{f} I_{d f}+v_{s q} \\
P_{f}=v_{d f} I_{d f}+v_{q f} I_{q f} \\
Q_{f}=v_{q f} I_{d f}-v_{d f} I_{q f}
\end{array}\right.
$$

\section{Non-Linear Controllers Synthesis}

The main objective of the DFIG-based WECS control is to maintain a constant stator voltage amplitude and frequency when the wind speed is changed. For this reason, the presence of a controller is very necessary. Many control techniques are developed in the literature for such systems. However, the implementation of these controllers seems very complicated. In this work, two non-linear controllers are developed:

a) SLIDING MODE controller.

b) BACKSTEPPING controller.

\subsection{Sliding Mode Controller Design}

The variable structure system (VSS) is a system whose structure changes during its operation. It is characterized by the choice of a structure and a switching logic. This latter allows the system to switch from one structure to another at any time by the choice of a function, which separates the state space into two parts, and an appropriate switching logic. The Sliding mode technique is a special case of (VSS). It consists of forcing the system state trajectory to attain a hyper surface in finite time and then stay there. This latter presents a relation between the system state variables which defines a differential equation, and consequently, determines the system dynamics if it remains on the hyper surface. The evolution of a system subject to a control law no longer depends on the system or the external disturbances, but on the properties of the hyper surface. The system will therefore be robust to uncertainties (specific to the system) and disturbances (external to the system) but will be totally insensitive [19], [25-28].

\subsubsection{RSC Control using Sliding Mode Controller}

The sliding surface proposed by J.SLOTINE is given by [29]:

$$
S(X)=\left(\frac{d}{d t}+\delta\right)^{n-1} e(X)
$$

We take $\mathrm{n}=1$, we obtain:

$$
\left\{\begin{array}{c}
s\left(P_{s}\right)=P_{s r e f}-P_{s} \\
s\left(Q_{s}\right)=Q_{\text {sref }}-Q_{s}
\end{array}\right.
$$


The derivative of sliding surface is given by:

$$
\left\{\begin{array}{l}
\dot{S}(P s)=I_{s r e f}^{\&}+\frac{V_{s} \cdot M}{L_{S}} \cdot\left(\frac{V_{r q e q}+V_{r q n}}{L_{r} \cdot \sigma}-\frac{R_{r}}{L_{r} \cdot \sigma} \cdot I_{r q}-\omega_{r} \cdot I_{r d}-\omega_{r} \cdot V_{s} \cdot \frac{M}{L_{r} \cdot L_{s} \cdot \omega_{s} \cdot \sigma}\right) \\
\dot{S}(Q s)=\mathcal{Q}_{s r e f}^{\&}+V_{s} \cdot \frac{M}{L_{S}} \cdot\left(\frac{V_{r d e q}+V_{r d n}}{L_{r} \cdot \sigma}-\frac{R_{r}}{L_{r} \cdot \sigma} \cdot I_{r d}+\omega_{r} \cdot I_{r q}\right)
\end{array}\right.
$$

During the sliding and permanent mode, we have:

$$
S_{(P s, Q s)}=0, \dot{S}_{(P s, Q s)}=0, V_{r d n}=V_{r q n}=0
$$

The expression of the equivalent command becomes:

$$
\left\{\begin{array}{l}
V_{r d e q}=-\frac{L_{r} \cdot L_{s} \cdot \sigma}{M \cdot V_{s}} \cdot \mathcal{Q}_{s r e f}+R_{r} \cdot I_{r d}-\omega_{r} \cdot L_{r} \cdot \sigma \cdot I_{r q} \\
V_{r q e q}=-L_{r} \cdot L_{s} \cdot \frac{\sigma}{V_{s} \cdot M} \cdot I_{s r e f}+R_{r} I_{r q}+L_{r} \cdot \omega_{r} \cdot \sigma \cdot I_{r d}+\omega_{r} \cdot M \cdot \frac{V_{s}}{L_{s} \cdot \omega_{s}}
\end{array}\right.
$$

Therefore, the stabilizing control is given by the following equation:

$$
\left\{\begin{array}{l}
V_{r d n}=K_{d} \operatorname{sat}(S(P s)) \\
V_{r q n}=K_{q} \operatorname{sat}(S(Q s))
\end{array}\right.
$$

\subsubsection{GSC Control using Sliding Mode Controllers}

We consider the SLOTINE's sliding mode surface. For $\mathrm{n}=1$, we obtain:

$$
\left\{\begin{array}{c}
S\left(P_{f}\right)=P_{f r e f}-P_{f} \\
S\left(Q_{f}\right)=Q_{f r e f}-Q_{f}
\end{array}\right.
$$

The derivative of the sliding surface is given by:

$$
\left\{\begin{array}{c}
\dot{S}\left(P_{f}\right)=I_{f r e f}+\frac{V_{s} \cdot R_{f}}{L_{f}} \cdot I_{q f}+\frac{V_{s}\left(V_{q f e q+} V_{q f n}\right)}{L_{f}}+w_{s} \cdot V_{s} \cdot I_{d f}-\frac{V_{s}^{2}}{L_{f}} \\
\dot{S}\left(Q_{f}\right)=\mathcal{Q}_{\text {fref }}-\frac{V_{s} \cdot R_{f}}{L_{f}} \cdot I_{d f}-\frac{V_{s}\left(V_{d f e q+} V_{d f n}\right)}{L_{f}}+w_{s} \cdot V_{s} \cdot I_{q f}
\end{array}\right.
$$

In the sliding and permanent mode, we obtain the expression of the equivalent command supplied as follows:

$$
\left\{\begin{array}{c}
V_{d f e q}=\frac{L_{f}}{V_{s}} \cdot Q_{f r e f}-R_{f} \cdot I_{d f}+L_{f} \cdot w_{s} \cdot I_{q f} \\
V_{q f e q}=-\frac{L_{f}}{V_{s}} \cdot \&_{\text {fref }}-R_{f} \cdot I_{q f}-L_{f} \cdot w_{s} \cdot I_{d f}+V_{s}
\end{array}\right.
$$

The stabilizing control is expressed by:

$$
\left\{\begin{array}{l}
V_{d f n}=K_{d f n} \text { sat }\left(S\left(P_{f}\right)\right) \\
V_{q f n}=K_{q f n} \operatorname{sat}\left(S\left(Q_{f}\right)\right)
\end{array}\right.
$$

\subsection{Backstepping Controller Design}

The principle of Backstepping control is based on the decomposition of the entire control system, which is generally multivariable and of high order into a cascade of first-order control subsystems. For each subsystem, a so-called virtual control law is calculated. The latter will serve as a reference for the next subsystem until obtaining the control law for the complete system. Moreover, this technique has the advantage of preserving the non-linearity's useful for the performance and the robustness of the control, 
unlike the linearization methods. The determination of control laws that follows from this approach is based on the use of control Lyapunov functions [22-24].

\subsubsection{RSC Control using BACKSTEPPING Controller}

The synthesis of this control can be achieved in two steps :

Step 1: Calculation of reference rotor currents:

In this step, we define the error between the active and reactive stator powers and their references. The errors of the stator power are defined by:

$$
\left\{\begin{array}{c}
e_{1}=P_{\text {sref }}-P_{s} \\
e_{2}=Q_{\text {sref }}-Q_{s}
\end{array}\right.
$$

The derivative of the errors is given by:

$$
\left\{\begin{array}{l}
\dot{e}_{1}=I_{s r e f}^{\&}+\frac{V_{s} \cdot M}{L_{s}} \cdot\left(\frac{V_{r q}}{L_{r} \cdot \sigma}-\frac{R_{r}}{L_{r} \cdot \sigma} \cdot I_{r q}-\omega_{r} \cdot I_{r d}-\omega_{r} \cdot V_{s} \cdot \frac{M}{L_{r} \cdot L_{s} \cdot \omega_{s} \cdot \sigma}\right) \\
\dot{e}_{2}=\mathcal{Q}_{s r e f}^{\&}+V_{s} \cdot \frac{M}{L_{S}} \cdot\left(\frac{V_{r d}}{L_{r} \cdot \sigma}-\frac{R_{r}}{L_{r} \cdot \sigma} \cdot I_{r d}+\omega_{r} \cdot I_{r q}\right)
\end{array}\right.
$$

We first choose the candidate function of " LYAPUNOV "associated with the active and reactive stator power errors, in the following quadratic form:

$$
V_{1}=\frac{1}{2} e_{1}^{2}+\frac{1}{2} e_{2}^{2}
$$

Its derivative is given by:

$$
\dot{V}_{1}=e_{1} \dot{e}_{1}+e_{2} \dot{e_{2}}
$$

By replacing the error by their expression, we obtain:

$$
\begin{aligned}
& \dot{V}_{1}=e_{1}\left(I_{s r e f}^{\&}+\frac{V_{s} \cdot M}{L_{s}} \cdot\left(\frac{V_{r q}}{L_{r} \cdot \sigma}-\frac{R_{r}}{L_{r} \cdot \sigma} \cdot I_{r q}-\omega_{r} \cdot I_{r d}-\omega_{r} \cdot V_{s} \cdot \frac{M}{L_{r} \cdot L_{s} \cdot \omega_{s} \cdot \sigma}\right)\right)+ \\
& e_{2}\left(\mathcal{Q}_{s r e f}^{\&}+V_{s} \cdot \frac{M}{L_{s}} \cdot\left(\frac{V_{r d}}{L_{r} \cdot \sigma}-\frac{R_{r}}{L_{r} \cdot \sigma} \cdot I_{r d}+\omega_{r} \cdot I_{r q}\right)\right)
\end{aligned}
$$

In order to ensure the stability of the subsystem according to LYAPUNOV, the derivative of $V 1$ must be negative. So, we choose it in the following form:

$$
\dot{V}_{1}=-K_{1} e_{1}^{2}-K_{2} e_{2}^{2} \leq 0
$$

With: ${ }_{1}, k_{2}$ are positive constants.

Equalizing the two equations, we obtain the virtual command Ird and Irq defined by:

$$
\left\{\begin{array}{l}
I_{r q r e f}=\frac{L_{r} \cdot \sigma \cdot L s}{V_{s} \cdot R_{S} \cdot M}\left(I_{s r e f}^{\&}+K_{1} e_{1}+\frac{V_{s} \cdot M}{L_{s} \cdot L_{r} \cdot \sigma}\left(V_{r q}-L_{r} \cdot \sigma \cdot \omega_{r} \cdot I_{r d}-g \frac{M \cdot V_{s}}{L_{S}}\right)\right) \\
I_{\text {rdref }}=\frac{L_{r} \cdot \sigma \cdot L s}{V_{s} \cdot R_{s} \cdot M}\left(\dot{Q}_{s r e f}+K_{2} e_{2}+\frac{V_{s} \cdot M}{L_{s} \cdot L_{r} \cdot \sigma}\left(V_{r d}+L_{r} \cdot \sigma \cdot \omega_{r} \cdot I_{r q}\right)\right)
\end{array}\right.
$$

$I_{\text {rdref }}$ and $I_{\text {rqref }}$ will be considered as reference to the following subsystem.

Step 2: Calculation of rotor voltages:

In this last step, it has been possible to deduce the true control law Vrq and Vrd which makes it possible to reach the design objectives for the global system. The errors of the rotor currents are defined by:

$$
\left\{\begin{array}{l}
e_{3}=I_{\text {rqref }}-I_{\text {rq }} \\
e_{4}=I_{\text {rdref }}-I_{\text {rd }}
\end{array}\right.
$$


The derivative of the errors is given by:

$$
\left\{\begin{array}{l}
\dot{e} 3=\dot{I}_{\text {rqref }}-\frac{1}{L_{r} \cdot \sigma} \cdot\left(V_{r q}-R_{r} . I_{r q}-L_{r} \cdot \sigma \cdot \omega_{r} \cdot I_{r d}-g \cdot \frac{M \cdot V_{s}}{L_{s}}\right) \\
\dot{e} 4=\dot{I}_{r d r e f}-\frac{1}{L_{r} \cdot \sigma}\left(V_{r d}-R_{r} . I_{r d}+L_{r} \cdot \sigma \cdot \omega_{r} . I_{r q}\right)
\end{array}\right.
$$

The extended LYAPUNOV function is defined by:

$$
V_{2}=\frac{1}{2} e_{1}^{2}+\frac{1}{2} e_{2}^{2}+\frac{1}{2} e_{3}^{2}+\frac{1}{2} e_{4}^{2}
$$

Its derivative becomes as follows:

$$
V_{2}=e_{1} e_{1}+e_{2} e_{2}+e_{3} e_{3}+e_{4} e_{4}=V_{1}+e_{3} e_{3}+e_{4} e_{4}
$$

In order to ensure the stability of the system according to LYAPUNOV, the devivative of $V 2$ must be negative. So, we choose it in the following form:

$$
\dot{V}_{2}=-K_{1} e_{1}^{2}-K_{2} e_{2}^{2}-K 3 e_{3}^{2}-K_{2} e_{2}^{2} \leq 0
$$

Equalizing the two equations, we obtain:

$$
\left\{\begin{array}{l}
e_{3}\left(\dot{I}_{r q r e f}-\frac{1}{L_{r} \cdot \sigma} \cdot\left(V_{r q}-R_{r} \cdot I_{r q}-\omega_{r} \cdot L_{r} \cdot \sigma \cdot I_{r d}-g \cdot \frac{M \cdot V_{s}}{L_{s}}\right)\right)=-K_{3} e_{3}^{2} \\
e_{4}\left(\dot{I}_{r d r e f}-\frac{1}{L_{r} \cdot \sigma} \cdot\left(V_{r d}-R_{r} \cdot I_{r d}+\omega_{r} \cdot L_{r} \cdot \sigma \cdot I_{r q}\right)\right)=-K_{4} e_{4}^{2}
\end{array}\right.
$$

Which gives the expression global real command Vrd and Vrq defined by:

$$
\left\{\begin{array}{l}
V r d=L_{r} \cdot \sigma\left(K_{4} e_{4}+\dot{I}_{r d r e f}+\frac{1}{L_{r} \cdot \sigma} \cdot\left(R_{r} \cdot I_{r d}-\omega_{r} \cdot L_{r} \cdot \sigma \cdot I_{r q}\right)\right) \\
V r q=L_{r} \cdot \sigma\left(K_{3} e_{3}+\dot{I}_{r q r e f}+\frac{1}{L_{r} \cdot \sigma} \cdot\left(R_{r} \cdot I_{r q}+\omega_{r} \cdot L_{r} \cdot \sigma \cdot I_{r d}+g \cdot \frac{M \cdot V_{s}}{L_{S}}\right)\right)
\end{array}\right.
$$

Hence, the asymptotic stability of the origin.

\subsubsection{GSC control using Backstepping controllers}

The powers exchanged between the Grid Side Converter and network are expressed by [21]:

$$
\left\{\begin{array}{c}
P_{f}=v_{q s} I_{q f} \\
Q_{f}=-v_{q s} I_{d f}
\end{array}\right.
$$

The expression of the filter currents is presented by the following equation:

$$
\left\{\begin{array}{l}
\dot{I_{d f}}=-\frac{V_{d f}}{L_{f}}-\frac{\boldsymbol{R}_{f}}{\boldsymbol{L}_{f}} I_{d f}+w_{s} \boldsymbol{I}_{q f} \\
\dot{\boldsymbol{I}_{q f}}=-\frac{\boldsymbol{V}_{q f}}{\boldsymbol{L}_{f}}-\frac{\boldsymbol{R}_{f}}{\boldsymbol{L}_{f}} \boldsymbol{I}_{q f}-\boldsymbol{w}_{s} \boldsymbol{I}_{d f}+\frac{\boldsymbol{V}_{s}}{\boldsymbol{L}_{f}}
\end{array}\right.
$$

According to these equations, we notice that the active and reactive powers are linked by the filter currents. So, it is sufficient to control the currents of the filter; the direct component Iqf controls the active power of the filter Pf and the quadratic component Idf controls the reactive power of the filter Qf.The errors of the filter currents e5 and e6 are defined by: 


$$
\left\{\begin{array}{l}
e_{5}=I_{\text {dfref }}-I_{d f} \\
e_{6}=I_{\text {qfref }}-I_{q f}
\end{array}\right.
$$

The derivatives of the errors are given by:

$$
\left\{\begin{array}{l}
\dot{e}_{5}=I d \dot{f r e f}+\frac{V_{d f}}{L_{f}}+\frac{R_{f}}{\boldsymbol{L}_{f}} I_{d f}-w_{s} I_{q f} \\
\dot{\boldsymbol{e}}_{6}=I q \dot{f} \dot{r} e f+\frac{V_{q f}}{\boldsymbol{L}_{f}}+\frac{\boldsymbol{R}_{f}}{\boldsymbol{L}_{f}} \boldsymbol{I}_{q f}+w_{s} \boldsymbol{I}_{d f}-\frac{V_{s}}{\boldsymbol{L}_{f}}
\end{array}\right.
$$

We choose the candidate function of " LYAPUNOV " associated with the filter current errors, in the following quadratic form:

$$
V_{3}=\frac{1}{2} e_{5}^{2}+\frac{1}{2} e_{6}^{2}
$$

Its derivative is given by:

$$
\dot{V}_{3}=e_{5}\left(I d \dot{f} r e f+\frac{V_{d f}}{L_{f}}+\frac{R_{f}}{L_{f}} I_{d f}-w_{s} I_{q f}\right)+e_{6}\left(I q \dot{f} r e f+\frac{V_{q f}}{L_{f}}+\frac{R_{f}}{L_{f}} I_{q f}+w_{s} I_{d f}-\frac{V_{s}}{L_{f}}\right)
$$

So as to ensure the stability of the subsystem according to LYAPUNOV, The derivative of $\mathrm{V}_{3}$ must be negative. So, we choose it in the following form:

$$
\dot{V}_{3}=-K_{5} e_{5}^{2}-K_{6} e_{6}^{2} \leq 0
$$

With:,$k_{6}$ are positive constants.

By doing the equality between the two equations, we get:

$$
\begin{aligned}
& e_{5}\left(I d \dot{f} r e f+\frac{V_{d f}}{L_{f}}+\frac{R_{f}}{L_{f}} I_{d f}-w_{s} I_{q f}\right)+e_{6}\left(I q \dot{f} r e f+\frac{V_{q f}}{L_{f}}+\frac{R_{f}}{L_{f}} I_{q f}+w_{s} I_{d f}-\frac{V_{s}}{L_{f}}\right) \\
& =-K_{5} e_{5}^{2}-K_{6} e_{6}^{2}
\end{aligned}
$$

Which gives the expression of the actual global command Vfd and Vfq defined by:

$$
\left\{\begin{array}{l}
V_{d f}=-L_{f}\left(K_{5} e_{5}+I d \dot{f} \dot{r} e f+\frac{R_{f}}{L_{f}} I_{d f}+w_{s} I_{q f}\right) \\
V_{q f}=-L_{f}\left(K_{6} e_{6}+I q \dot{f} \dot{r} e f+\frac{R_{f}}{L_{f}} I_{q f}+w_{s} I_{d f}-\frac{V_{s}}{L_{f}}\right)
\end{array}\right.
$$

\section{RESULTS AND DISCUSSION}

To gauge the performance of the wind system based on the Doubly Fed Induction Generator, we tested the operation of the wind system by two types of control: the sliding mode technique and the BACKSTEPPING one in order to control the powers generated by the DFIG. To carry out this work, two tests were performed using MATLAB / Simulink:

a) Test 1: Tracking and regulation tests for SMC and Backstepping Controller.

b) Test 2: The robustness tests regarding the variation parameters.

The results obtained for the various simulation tests, are respectively exposed on the following Figures:

\subsection{Tracking and Regulation Tests}

In this case, we consider the aerodynamic power according to the MPPT strategy as a reference for the stator active power of the DFIG and zero as a reference of the stator reactive power to guarantee a unit power factor on the stator side to optimize the quality of the energy reverted on the grid. 


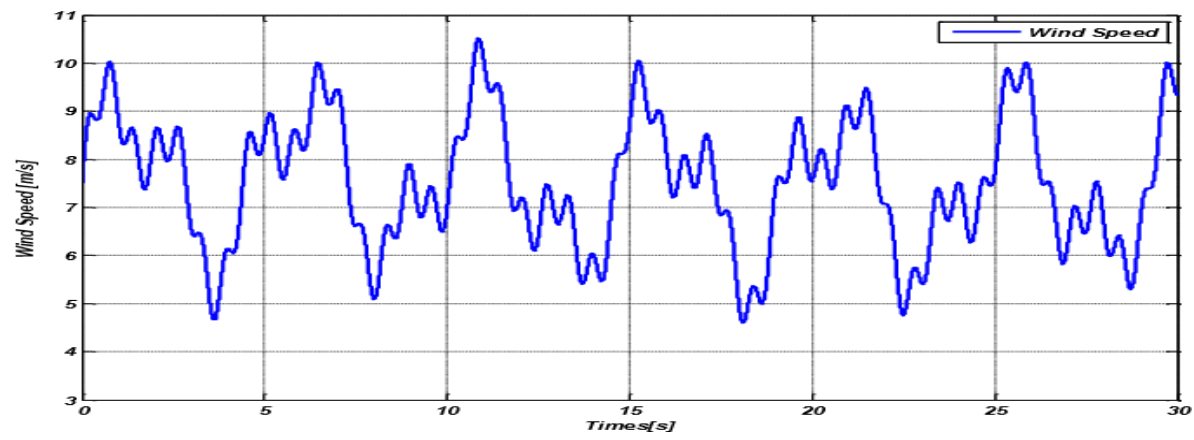

Figure 2. The wind speed $[\mathrm{m} / \mathrm{s}]$
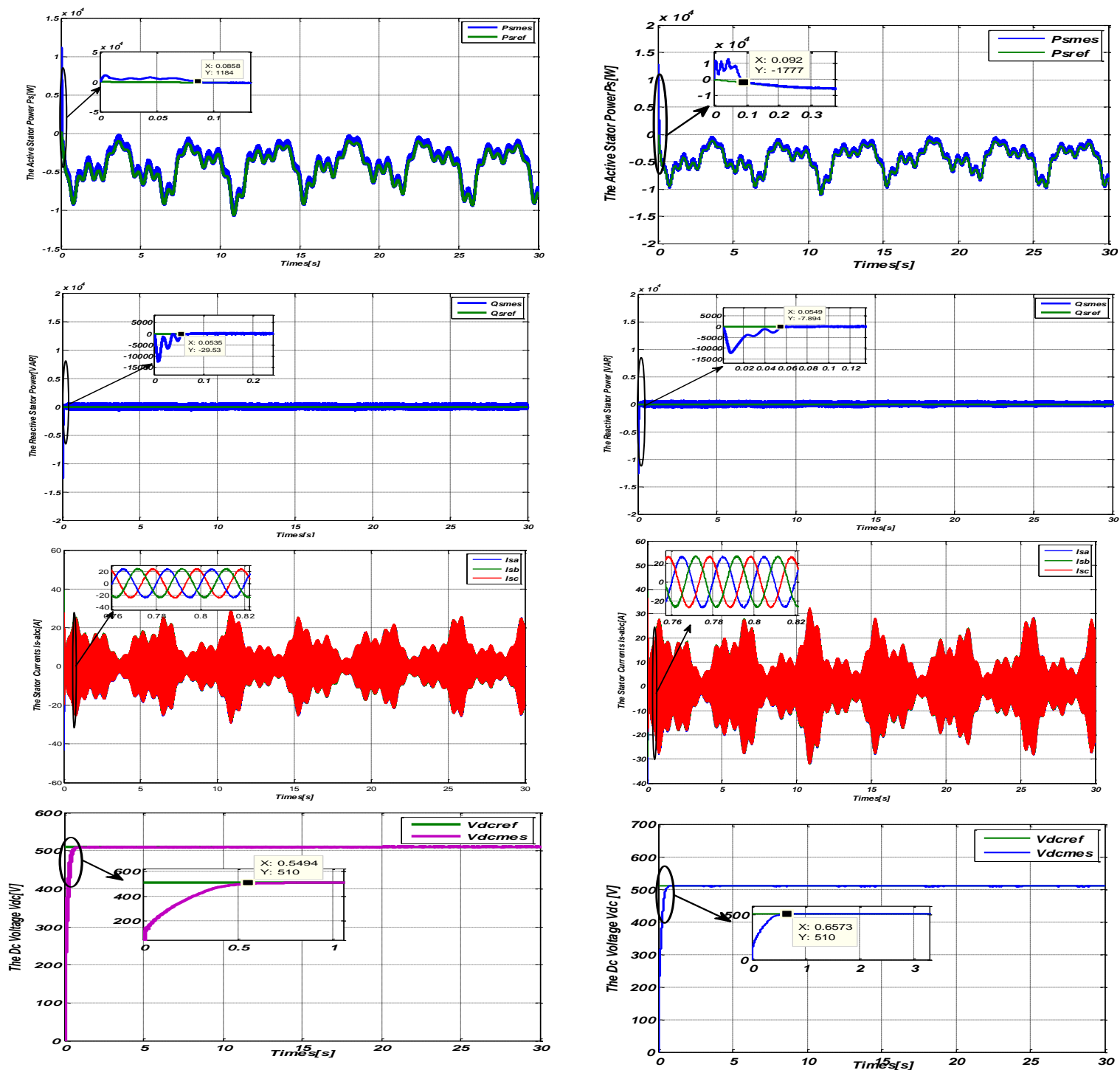

Figure 3. Tracking test using SMC

Figure 4. Tracking test using BS

From these figures we can note that the references of the powers are well followed by the generator for both controller without coupling effect between the two axes with a low response time for Sliding Mode controller (Table.1). The active stator power Ps is negative means that the Grid receives the energy produced by the DFIG. The reactive stator power is null which gives a unit power factor. The stator voltages are a sinusoidal form with a fixed frequency $50 \mathrm{~Hz}$ which implies a clean energy exchanges between the stator and 
the Grid. Using the FFT (Fast Fourier Transform). The total harmonic distortion (THD=2.36\%) for backstepping is reduced compared to sliding mode $(\mathrm{THD}=3.99 \%)$ due to chattering phenomenon.

Table 1. Summarization table of the response time SMC and Backstepping Controller

\begin{tabular}{ccc}
\hline Response time & SMC Controller & Backstepping Controller \\
\hline Active Power Ps & 0.0858 & 0.09 \\
Reactive Power Qs & 0.0535 & 0.0549 \\
Dc-Bus & 0.5494 & 0.6573 \\
\hline
\end{tabular}

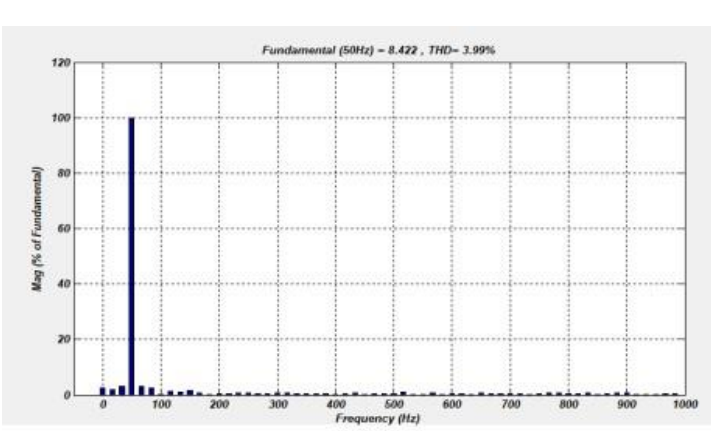

Figure 5. Spectrum harmonic for SMC

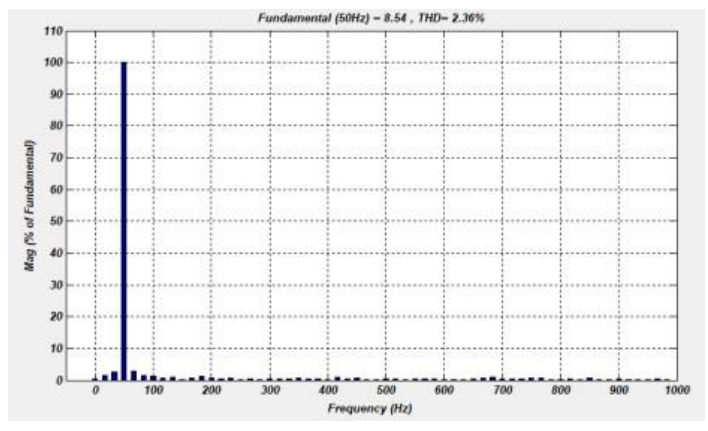

Figure 6. Spectrum harmonic for Backstepping

\subsection{Robustness Tests}

The previous test was done considering the fixed machine parameters, but these parameters can be influenced by several physical phenomena such as the temperature which allows the increase of the resistance values, the saturation of the inductors etc... In addition, the identification of these parameters is expressed in infidelities owing to measuring devices and the adopted methodology. Therefore, it is interesting to compare the performance of both systems regarding this phenomenon. To test the performance of each controller against model uncertainties affecting system stability, we replace the parameters of the system used in the DFIG by the following equation:

$$
\left\{R_{(s, r)}=0.8 R_{n}, L_{(s, r)}=1.8 L_{n}\right.
$$
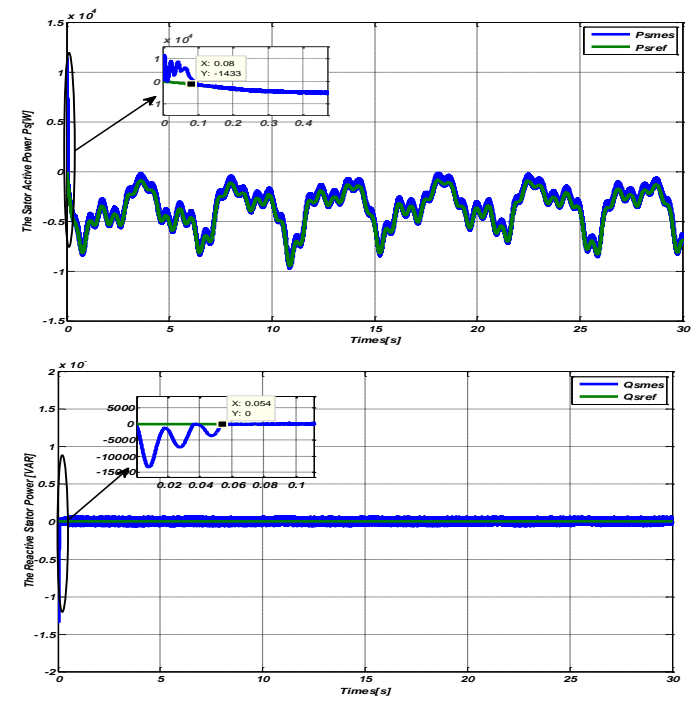

Figure 7. Robustness test using SMC
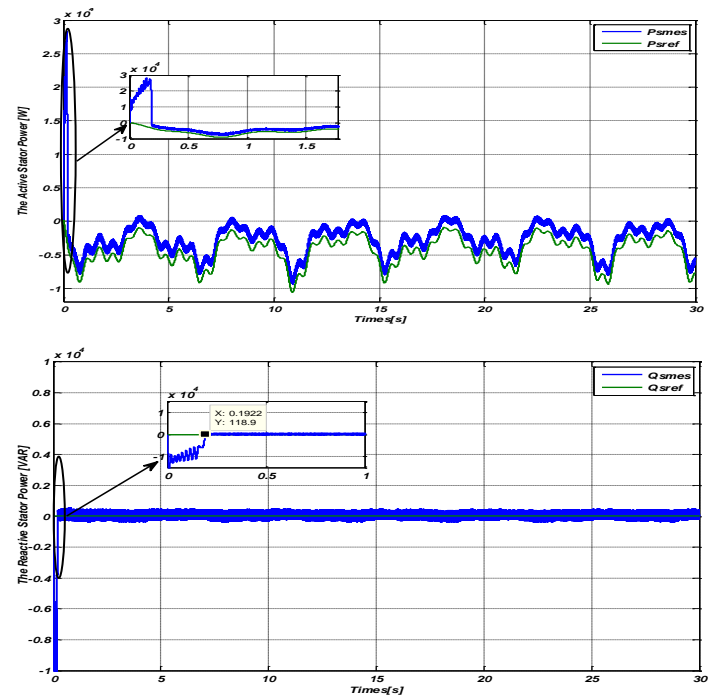

Figure 8. Robustness test using Backsteping 


\section{CONCLUSION}

This work presents a nonlinear power control of doubly-fed induction generator integrated in the Wind System. First, the model of the doubly fed induction generator under the park referential is presented. Secondly, a control strategy using sliding mode and backstepping is shown. The simulation results demonstrate the performance of the controllers. It is clear that the disadvantage of sliding mode is the chattering phenomenon that generates the harmonics and helps to stress the mechanical part, while the problem of the backstepping is not robust against the machine variation parameters. All this leads us to think of other improvements such as moving to a higher order sliding mode to eliminate the chattering phenomenon and the adaptive backstepping control to make the system robust, or to hybridize the two techniques of control.

\section{REFERENCES}

[1] X. S. Li, et al., "Analysis and Simplification of Three-Dimensional Space Vector PWM for Three-Phase Four-Leg Inverters," IEEE Transactions on Industrial Electronics, vol. 58, pp. 450-464, Feb 2011.

[2] Canudas, D., Commande des moteurs asynchrone, modélisation contrôle vectoriel et DTC, HERMES/LAVOISIER, Paris, (2000).

[3] Gille, J. C., Decaulne, P., \& Pélegrin, M. "Systèmes asservis non linéaires”, 5, Dunod. (1975).

[4] LOUCIF, M., "Synthèse de lois de commande non-linéaires pour le contrôle d'une machine asynchrone à double alimentation dédiée à un système aérogénérateur", Phd.Thesis, Université Aboubakr Belkaïd, Faculté de TECHNOLOGIE-Tlemcen-, (2016).

[5] Thedrane, Y., EL Bekkali, C., Bossoufi, B. , "Power Control of DFIG-generators for Wind Turbines Variable-speed. ”, International Journal of Power Electronics and Drive Systems (IJPEDS) ,8(1):444-453, (2017).

[6] Ihedrane, Y., EL Bekkali, C. , Bossoufi, B. , "Direct and indirect field oriented control of DFIG-generators for wind turbines variable-speed.', 14th International Multi-Conference on Systems, Signals \& Devices (SSD), Marrakech Morocco-, 28-31 (March 2017).

[7] Thedrane, Y., \& Bossoufi, B. (2017, December). Power Control of Wind Turbine System based on DFIGGenerator, using Sliding Mode Technique. In 2017 International Renewable and Sustainable Energy Conference (IRSEC) (pp. 1-6). IEEE.

[8] Ihedrane, Y., El Bekkali, C., Bossoufi, B., \& Bouderbala, M. (2019). Control of Power of a DFIG Generator with MPPT Technique for Wind Turbines Variable Speed. In Modeling, Identification and Control Methods in Renewable Energy Systems (pp. 105-129). Springer, Singapore.

[9] Mensou, S., Essadki, A., Nasser, T., \& Idrissi, B. B. (2017). An Efficient Nonlinear Backstepping Controller Approach of a Wind Power Generation System Based on a DFIG. International Journal of renewable Energy Research, 7(4).

[10] Bossoufi, B., Karim, M., Ionita, S., \& Lagrioui, A. (2011). The optimal direct torque control of a PMSM drive: FPGA-based implementation with MATLAB \& Simulink simulation. Journal of Theoretical and Applied Information Technology JATIT, 28(2), 63-72.

[11] N. El Ouanjli, et al., "High Performance Direct Torque Control of Doubly Fed using Fuzzy Logic," Gazi University Journal of Science, vol.31, No. 2, pp. 532-542, 2018.

[12] H. Mahmoudi, M. El Ghamrasni, A. Lagroui, B. Bossoufi 2005-2015 « Backstepping adaptative control of DFIGGENERATORS for wind turbine variable-speed, Journal of theorical and appliend information technology, 2nd ed., vol. 82. P.321-330.

[13] M.El Ghamrasni, H.Mahmoudi and B.Bossoufi "Modelling and simulation of a wind system using variable wind regimes with Backstepping control of DFIG ", 2 IOP Conference Series: Earth and Environmental Science, Volume 161, conference 1.

[14] Taoussi, M., Karim, M., Bossoufi, B., Hammoumi, D., Lagrioui, A., \& Derouich, A. (2016). Speed variable adaptive backstepping control of the doubly-fed induction machine drive. International Journal of Automation and Control, 10(1), 12-33.

[15] Bossoufi, B., Aroussi, H. A., Ziani, E. M., Karim, M., Lagrioui, A., Derouich, A., \& Taoussi, M. (2014, October). Robust adaptive Backstepping control approach of DFIG generators for wind turbines variable-speed. In Renewable and Sustainable Energy Conference (IRSEC), 2014 International (pp. 791-797). IEEE.

[16] El Ouanjli, N., Derouich, A., El Ghzizal, A., El Mourabit, Y., \& Taoussi, M. (2017). Contribution to the Improvement of the Performances of Doubly Fed Induction Machine Functioning in Motor Mode by the DTC Control. International Journal of Power Electronics and Drive Systems (IJPEDS), 8(3), 1117-1127.

[17] El Ouanjli, N., Derouich, A., El Ghzizal, A., Chebabhi, A., Taoussi, M., \& Bossoufi, B. (2018). Direct Torque Control Strategy Based on Fuzzy Logic Controller for a Doubly Fed Induction Motor. In IOP Conference Series: Earth and Environmental Science, 161(1), p. 012004.

[18] El Ouanjli, N., Derouich, A., El Ghzizal, A., Chebabhi, A., Taoussi, M., \& Bossoufi, B. (2018). Direct Torque Control Strategy Based on Fuzzy Logic Controller for a Doubly Fed Induction Motor. In IOP Conference Series: Earth and Environmental Science, 161(1), p. 012004.

[19] Buhler, H., "Réglage par mode de glissement", Première Edition. éd., Lausanne, Suisse: Presses Polytechniques et Universitaires Romandes.( 1986),

[20] BEKAKRA,Y., "Contribution à l'Etude et à la Commande Robuste d'un Aérogénérateur Asynchrone à Double Alimentation.”, Phd.Thesis, Université Mohamed Khider, Biskra., (2014). 
[21] TAMAARAT, A., "Modélisation et commande d'un système de conversion d'énergie éolienne à base d'une MADA.', Phd.Thesis, Université Mohamed Khider, Biskra, (2015).

[22] Bossoufi, B., Ionita, S., Constantinescu, L., Alami Arroussi , H., El Ghamrasni, M. , \& Thedrane, Y., "Managing voltage drops: a variable speed wind turbine connected to the grid", International Journal of Automation and Control , 11(1):15-34,(2017)

[23] Bossoufi, B., Karim, M., Lagrioui, A., Taoussi, M., Derouich, A., "Observer backstepping control of DFIGGenerators for wind turbines variable-speed: FPGA-based implementation.” Renewable Energy (ELSIVER), 81: 903-917,( 2015)

[24] B.Bossoufi, M.Karim, A.Lagrioui, M.Taoussi, A.Derouich "Modeling and Backstepping Control of DFIG Generators for Wide-Range Variable-speed Wind Turbines" Journal of Journal of Electrical Systems JES, pp317-330. Vol.10 No.3, September 2014.

[25] Bekakra,Y., Ben Attous, D., "DFIG sliding mode control fed by back-to-back PWM converter with DC-link voltage control for variable speed wind turbine," Frontiers in Energy, $8: 345-354$, (2014).

[26] MACHMOUM, M. et POITIERS,F.,"Sliding mode control of a variable speed wind energy conversion system with DFIG."',Ecologic vehicles; renewable energies, MONACO,(March 2009).

[27] Bregeault, V., "Quelques contributions à la théorie de la commande par modes glissants.", Phd.Thesis, Ecole Centrale de Nantes (ECN). (2010).

[28] Slotine, J. J., and W. Li., “Applied Nonlinear Control, Prentice-Hall, Englewood Cliffs, NJ, 1991.’, 461, Google Scholar (1998).

[29] Hashimoto, H., Yamamoto, H., Yanagisawa, S., \& Harashima, F., "Brushless servo motor control using variable structure approach", IEEE Transactions on industry applications, 24(1), 160-170, (1988).

[30] HAMDI, N., "Amélioration des performances des aérogénérateurs. ", Phd.Thesis, Universite Constantine I, (2013). 